\title{
Determinação da razão ótima de espermatozóides por ovócitos de piabanha Brycon insignis (pisces - characidae)
}

\author{
[Determination of the optimum ratio of spermatozoa per oocyte of the piabanha Brycon insignis] \\ E. Shimoda ${ }^{1,2,3}$, D.R. Andrade ${ }^{4}$, M.V. Vidal Júnior ${ }^{4}$, H.P. Godinho ${ }^{3}$, G.S. Yasui ${ }^{4}$ \\ ${ }^{1}$ Faculdade de Castelo - Castelo, ES \\ ${ }^{2}$ Universidade Cândido Mendes - Campos dos Goytacazes, RJ \\ ${ }^{3}$ Universidade Estácio de Sá - Rio de Janeiro, RJ \\ ${ }^{4}$ Universidade Estadual do Norte Fluminense - Campos dos Goytacazes, RJ \\ ${ }^{5}$ Pontifícia Universidade Católica - Belo Horizonte, MG
}

\begin{abstract}
RESUMO
Determinou-se a razão ótima de espermatozóides por ovócitos da piabanha Brycon insignis, utilizando-se dois machos e duas fêmeas da espécie, submetidos ao procedimento de desova induzida. Os gametas foram extrusados manualmente 200 horas-grau após a aplicação do extrato bruto de hipófise. Os ovócitos foram misturados e deste pool retiraram-se amostras com $2 \mathrm{~g}$ de ovócitos (701 ovócitos/g). O sêmen do pool foi diluído em solução de NaCL $1,2 \%$ de tal forma que, após a adição de $1 \mathrm{ml}$ do sêmen diluído aos ovócitos, fossem obtidas as seguintes razões espermatozóides por ovócitos em cada tratamento: $\mathrm{T} 1=86.662, \mathrm{~T} 2=173.324, \mathrm{~T} 3=259.986, \mathrm{~T} 4=346.648$ e $\mathrm{T} 5=433.310$. A taxa de fertilização do sêmen não diluído usado como controle foi de $65,3 \%$. Após ativação espermática com $\mathrm{NaHCO}_{3} 1 \%$ e fecundação, os ovos foram transferidos para as incubadoras e nelas foram observadas as seguintes percentagens de fertilização em relação à do grupo-controle: $\mathrm{T} 1=35,7 \%, \mathrm{~T} 2=53,1 \%, \mathrm{~T} 3=79,1 \%, \mathrm{~T} 4=93,4 \%$ e T5=87,8\%. A percentagem de fertilização (em relação ao controle) aumentou de forma linear, segundo a equação de regressão: $\hat{\mathrm{Y}}=15,55+0,0002297 \mathrm{X}\left(\mathrm{P}<0,01 ; \mathrm{R}^{2}=0,98\right)$, até a proporção de 314.481 espermatozóides por ovócitos, após o que a taxa de fertilização se estabilizou no limite de $88 \%$.

Palavras-chave: piabanha, Brycon insignis, razão ótima, espermatozóide, ovócito, fertilização
\end{abstract}

\begin{abstract}
The optimum spermatozoa:oocyte ratio of piabanha Brycon insignis was studied. Two males and two females were induced to spawn, and the gametes were stripped after 200 hourgrades starting from the application of carp pituitary gland. Oocytes from two females were mixed, and samples of $2 \mathrm{~g}$ (701 oocytes/g) were collected from the obtained pool and placed into plastic cups. The semen from the two males, after mixed to compose a pool, was diluted in $\mathrm{NaCl}$ solution (1.2\%) so that, after the addition of $1 \mathrm{ml}$ of diluted sperm into the oocytes, the following spermatozoa:oocyte ratios (tri-replicated) were obtained: $T 1=86,662, T 2=173,324, T 3=259,986, T 4=346,648$ and T5=433,310. After the activation using $1 \% \mathrm{NaHCO}_{3}$ and fertilization, the eggs were transferred to incubators, and observed the percentages of fertilization relative to the control. $T 1=35.7 \%, T 2=53.1 \%, T 3=79.1 \%, T 4=93.4 \%$ and T5 $=87.8 \%$. Undiluted semen was used as "control", which showed $65 \%$ of fertilization. The percentage of fertilization (relative to the control) increased linearly according to the regression $\hat{Y}=15.55+$ $0.0002297 X\left(P<0.01 ; R^{2}=0.98\right)$, until the proportion of 314,481 spermatozoa per oocyte, and, from this point, the fertilization rate maintained at $88 \%$.
\end{abstract}

Keywords: piabanha, Brycon insignis, optimum ratio, spermatozoon, oocyte, fertilization

Recebido para publicação em 20 de outubro de 2005

Aceito em 17 de maio de 2007

Endereço para correspondência (corresponding address)

Rua Dr. Lacerda Sobrinho, 246 (casa 15) - 28010-077 - Campos dos Goytacazes, RJ

E-mail: eduardo_shimoda@uol.com.br 


\section{INTRODUÇÃO}

A piabanha Brycon insignis é uma espécie de peixe encontrada apenas na bacia do rio Paraíba do Sul (Nomura, 1984), cuja população vem reduzindo-se rapidamente, em função de ações antrópicas, ao ponto de ser considerada oficialmente como em extinção (Instrução..., 2004). Planos de recuperação da população da espécie têm sido implantados nos últimos anos, incluindo o desenvolvimento de estudos a respeito da produção de alevinos para repovoamento (Andrade-Talmelli et al., 2001a,b; Sousa, 2004).

O teste de fertilização constitui o método que melhor permite avaliar a qualidade seminal (Ribeiro, 2001), sendo seu resultado expresso em percentagem de ovos que atingem a fase de fechamento do blastóporo. Embora os testes de fertilização tenham sido utilizados com freqüência em experimentos de criopreservação de sêmen (Silveira et al., 1984, 1990; Kavamoto et al., 1989; Cóser et al., 1992; Silva, 2000), poucos são os trabalhos no Brasil que determinam a razão ótima de espermatozóides por ovócitos.

Devido à dificuldade de obtenção de ovócitos considerados de boa qualidade (perfeitamente esféricos, translúcido e sem espaço perivitelínico), a capacidade fecundante do sêmen criopreservado tem sido avaliada em poucas espécies de peixes (Suquet et al., 1995). Outra dificuldade encontrada na avaliação da capacidade fecundante é a coleta de quantidades precisas de ovócitos. Por exemplo, os mesmos autores, ao coletarem 9 amostras consecutivas com $800 \mu \mathrm{l}$ de ova, observaram alto coeficiente de variação $(66,5 \%)$ no número de ovócitos em cada amostra.

Em truta Oncorhynchus mykiss, foi verificada correlação positiva entre percentagem de fertilização e motilidade quando foram usadas proporções menores que 200.000 espermatozóides por ovócito (Moccia e Munkittrick, 1987). Essa proporção foi indicada como a ideal para $O$. mykiss, sendo verificado porcentual de fertilização de $80,4 \%$ em trabalho realizado por Silveira et al. (1988). Os resultados podem ser contrastantes, considerando a mesma espécie. Silveira et al. (1984) obtiveram, como maior média, $78 \%$ de fertilização ao utilizarem
13 milhões de espermatozóides por óvulo de $O$. mykiss.

Suquet et al. (1995) realizaram experimento com a espécie marinha Scophthalmus maximus, verificando os percentuais de fertilização utilizando diversas proporções espermatozóides/ovócitos e ovócitos em estádios diferentes de maturação. Utilizando ovócitos maduros (estádio 3), obtiveram percentagens de fertilização que variaram entre 58,4\% a 93,9\% na proporção de 6000 espermatozóides/ovócito. Em proporções menores, o percentual de fertilização decresceu e o coeficiente de variação aumentou nos tratamentos. Em ovócitos em estádio 4, a variação na percentagem de fertilização foi muito alta, independente da proporção espermatozóides/ovócito.

A razão ótima de espermatozóides por ovócito foi estudada em outras espécies como a Thymallus thymallus (Lahnsteiner, 2000), Esox lucius (Marcel, 1981), Coregonus lavarelus (Lahnsteiner, 2000), Hippoglossus hipoglossus (Suquet et al., 1995), Cyprinus carpio (Marcel, 1981) e S. maximus (Suquet et al., 1995), sendo obtidos resultados que variaram de 6000 ( $T$. thymallus) a 1.600.000 (Scophthalmus maximus).

A obtenção da quantidade de espermatozóides para fertilizar uma determinada massa de ovócitos é importante na rotina de reprodução artificial, por permitir a otimização do sêmen, reduzindo o número de reprodutores e a área e gastos demandados para manutenção destes. Além disso, seria evitada a utilização de menos sêmen do que o necessário, o que poderia implicar em menores porcentuais de fertilização. O objetivo deste trabalho foi determinar a razão ótima de espermatozóides por ovócitos de piabanha Brycon insignis.

\section{MATERIAL E MÉTODOS}

Foram selecionados exemplares de piabanha Brycon insignis de ambos os sexos, presentes na estação experimental do Projeto Piabanha, em Itaocara, RJ, e que se apresentaram no estádio de maturação gonadal avançada, sendo escolhidas as fêmeas que apresentaram abdômen abaulado e papila genital avermelhada, e os machos que apresentaram saída de sêmen mediante massagem abdominal no sentido antero- 
posterior. Estes exemplares foram transportados ao laboratório e submetidos ao procedimento de hipofisação proposto por Woynarovich e Horvath (1983). As fêmeas receberam a dosagem preparatória de $0,5 \mathrm{mg}$ de extrato bruto de hipófise de carpa (EBHc) por quilograma de peso vivo. Decorridas 12 horas, foram aplicadas a dosagem final de $5,0 \mathrm{mg} \mathrm{EBHc} / \mathrm{kg}$ peso vivo, nas fêmeas, e a dosagem única de $0,5 \mathrm{mg}$ $\mathrm{EBHc} / \mathrm{kg}$ peso vivo, nos machos.

Após 200 horas-grau, procedeu-se a extrusão, primeiramente dos machos, sendo coletados $5 \mathrm{ml}$ de sêmen de cada macho em tubos de vácuo de $10 \mathrm{ml}$, após secagem da papila genital e das áreas adjacentes. Logo após a coleta, seguiram-se a adição de duas gotas de solução de $\mathrm{NaHCO}_{3} \quad 1 \%$ a uma gota de sêmen e a verificação da motilidade espermática subjetiva. As duas amostras apresentaram mais do que $90 \%$ de motilidade. Posteriormente, as amostras seminais foram misturadas para constituição de um pool, cuja motilidade observada foi de $90 \%$, a partir da qual se retiraram três alíquotas para determinação da concentração espermática. Procedeu-se, então, a pré-diluição da amostra, misturando-se $1 \mathrm{ml}$ do sêmen com $9 \mathrm{ml}$ de solução não ativadora, de $\mathrm{NaCl}$ 1,2\% (pré-diluição = 10 vezes). Essa solução foi diluída novamente, nas seguintes proporções de volume de sêmen prédiluído/volume de $\mathrm{NaCl} 1,2 \%$ : 1) $200 \mu \mathrm{l} / 3800 \mu \mathrm{l}$ (diluição total $=200$ vezes); 2 ) $400 \mu \mathrm{l} / 3600 \mu \mathrm{l}$ (diluição total $=100$ vezes); 3) $600 \mu 1 / 3400 \mu \mathrm{l}$ (diluição total $=66,7$ vezes); 4) $800 \mu 1 / 3200 \mu 1$ (diluição total $=50$ vezes); e 5) $1000 \mu 1 / 3000 \mu 1$ (diluição total $=40$ vezes).

Realizou-se, então, a extrusão das fêmeas. Ambas se mostraram preparadas fisiologicamente para a desova, haja vista a facilidade para a extrusão dos ovócitos. A papila genital e as regiões adjacentes (abdômen e nadadeira anal) foram secas, sendo a desova coletada em bacias plásticas secas, uma para cada fêmea. A seguir misturaram-se as desovas para constituição de um pool, do qual se retiraram três subamostras, com $1 \mathrm{~g}$ cada, que foram acondicionadas em tubos de vácuo de $10 \mathrm{ml}$, com formol, para contagem do número de ovócitos, realizada após duas horas.
A partir da amostra composta inicial, foram retiradas também amostras com 2,0g cada, e estas colocadas em copos plásticos de $300 \mathrm{ml}$ numerados de acordo com o tratamento utilizado. Para estabelecimento dos tratamentos, em cada copo plástico, foi utilizado $1 \mathrm{ml}$ de uma das diluições, sendo que cada tratamento teve três repetições. Ato imediato ao acréscimo do sêmen diluído, foram adicionados, a cada copo plástico, $2 \mathrm{ml}$ de $\mathrm{NaHCO}_{3} \quad 1 \%$ para ativação dos espermatozóides.

As diluições a partir do sêmen a fresco foram consideradas em concentrações de $24,3 \times 10^{9}$ espermatozóides/ml e adicionados $1 \mathrm{ml}$ de sêmen diluído nos $2 \mathrm{~g}$ de ovócitos (701 ovócitos/g), das quais se obtiveram as seguintes proporções de espermatozóides por ovócitos, utilizadas em cada tratamento: T1) 86.662; T2) 173.324; T3) 259.986; T4) 346.648; T5) 433.310.

Após a mistura do sêmen de cada tratamento com os ovócitos, para a fecundação, os ovos foram hidratados por 20min utilizando-se água destilada, após o que foram transferidos para as incubadoras. Cada repetição foi colocada em uma incubadora, constituída por uma garrafa transparente pet de 21 invertida, com tela para evitar a saída dos ovos. A entrada da água ocorreu pela parte inferior da garrafa invertida, ficando os ovos oxigenados e em suspensão durante seu desenvolvimento.

Os ovos permaneceram na incubadora na qual foi acompanhado o desenvolvimento embrionário, sendo que, nas primeiras 8 horas, foi realizada amostragem a cada duas horas e, posteriormente, a cada 30 minutos. Os primeiros ovócitos com fechamento de blastóporo foram observados após 8,5 horas de incubação. Decorridas mais de 1,5 horas, ou seja, 10 horas depois da colocação dos ovos na incubadora, foi verificada a percentagem de ovos fertilizados.

A seguir estimou-se a equação de regressão que melhor se ajustava aos dados, com as variações das taxas de fertilização (em relação ao controle) em função da quantidade de espermatozóides por ovócitos, sendo sua significância testada utilizando-se o aplicativo SAEG. Com base na equação, foi verificada a proporção ideal de espermatozóides por ovócitos. 


\section{RESULTADOS E DISCUSSÃO}

As médias das taxas de fertilização dos ovos de piabanha, em função das diferentes proporções de espermatozóides por ovócito utilizadas, podem ser observadas na Tab. 1 .

As taxas médias de fertilização aumentaram gradativamente até a proporção de 346.648 espermatozóides por ovócitos. Quando a proporção foi aumentada para 433.310, a percentagem de ovócitos fertilizados permaneceu praticamente a mesma. A tendência de estabilização torna-se mais nítida se for verificada a média de fertilização do controle, em que foi usado $1 \mathrm{ml}$ de sêmen sem diluição. As taxas médias de fertilização na proporção de 433.310 espermatozóides por ovócito foram próximas das obtidas no tratamento-controle, constituído de sêmen não diluído.

Obteve-se a equação de regressão descontínua $\hat{\mathrm{Y}}=15,55+0,0002297 \mathrm{X}\left(\mathrm{P}<0,01 ; \mathrm{R}^{2}=98,3\right)$, com platô iniciando-se 314.481 espermatozóides/ovócitos $\quad(87,8 \% \quad$ de fertilização), e foi possível estimar as taxas de fertilização em função das proporções de espermatozóides por ovócitos (Fig. 1).

Tabela 1. Taxa de fertilização (\%) ajustada em relação ao controle (média observada $=65,3 \%$ ) da piabanha Brycon insignis $(\mathrm{n}=3)$ verificadas em diferentes proporções de espermatozóides (sptz) por ovócito

\begin{tabular}{lccc}
\hline \multirow{2}{*}{ Tratamento } & Proporção & \multicolumn{2}{c}{ Taxa de fertilização (\%) em relação ao controle } \\
\cline { 3 - 4 } & SPTZ / Ovócitos & médias \pm desvio-padrão & CV (\%) \\
\hline T1 & 86.662 & $35,7 \pm 18,1$ & 50,7 \\
T2 & 173.324 & $53,1 \pm 36,3$ & 68,4 \\
T3 & 259.986 & $79,1 \pm 21,5$ & 27,2 \\
T4 & 346.648 & $93,4 \pm 32,7$ & 35,0 \\
T5 & 433.310 & $87,8 \pm 24,3$ & 27,7 \\
controle & 17.389 .444 & $100,0 \pm 26,7$ & 26,7
\end{tabular}

$\mathrm{T} 1=$ proporção de $\mathrm{spt}_{3} /$ ovócito de $86.662 ; \mathrm{T} 2=$ proporção de $173.324 ; \mathrm{T} 3=$ proporção de $259.986 ; \mathrm{T} 4=$ proporção de 346.648; T5= proporção de $433.310 . \mathrm{CV}=$ coeficiente de variação.

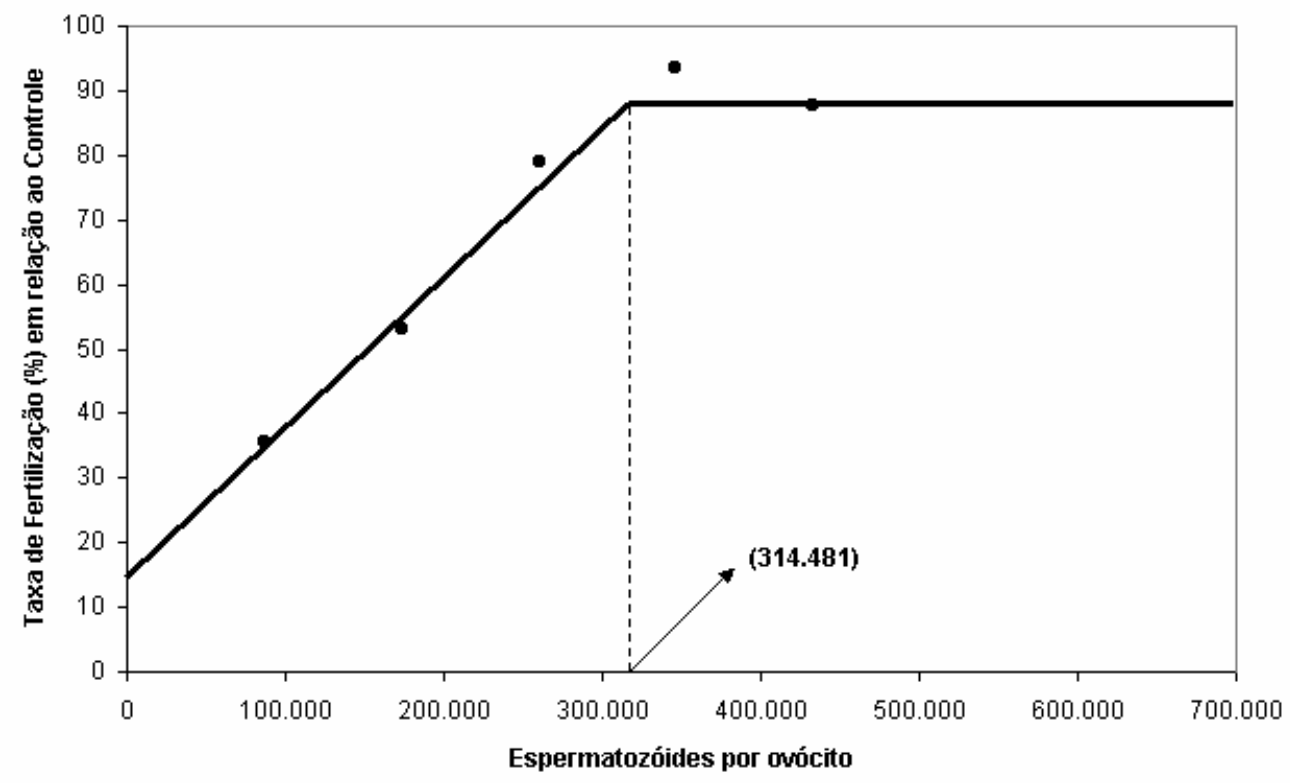

Figura 1. Equação de regressão descontínua (linear response plateau) da taxa de fertilização (ajustada em relação ao controle) em função da proporção de espermatozóides por ovócito de piabanha. 
Inicialmente, a taxa de fertilização $(\hat{Y})$, em relação ao controle, aumentou de forma linear com a proporção de espermatozóides por ovócito (X) seguindo a equação:

$\hat{\mathrm{Y}}=15,55+0,0002297 \mathrm{X}$, em que:

$\hat{\mathrm{Y}}=$ taxa de fertilização e $\mathrm{X}=$ espermatozóides por ovócito.

A taxa de fertilização aumentou até atingir o valor de $87,8 \%$, ajustado em relação ao controle, após o qual permaneceu constante neste platô (taxa máxima de fertilização). A mínima proporção necessária para que esse platô de $87,8 \%$ de fertilização seja atingido é de 314.481 espermatozóides/ovócito, considerada a razão ótima para que ocorra o máximo de fertilização dos ovos de piabanha.

Segundo Lahnsteiner (2000), a proporção ideal de espermatozóides por ovócito depende do diâmetro dos ovócitos. Espermatozóides de peixes fertilizam os ovócitos que entram por uma abertura denominada micrópila. Segundo Suquet et al. (1995), quanto menor o diâmetro do ovócito, maior a probabilidade de os espermatozóides alcançarem o aparato micropilar e fecundá-lo. Vazzoler (1996) descreve que a quantidade de ovócitos por grama tem inversa correlação com o tamanho desses gametas. Assim, quanto menores os ovócitos, maior a quantidade de ovócitos por grama e menor o seu diâmetro. No presente trabalho, o indicador do tamanho dos ovócitos foi a quantidade de ovócitos por grama. Embora o diâmetro do ovócito da piabanha não tenha sido medido no experimento de Sousa (2004), o autor verificou que, em situações experimentais, o ovócito mediu $1,3 \mathrm{~mm}$.

A razão ideal de aproximadamente $314 \times 10^{3}$ espermatozóides por ovócito obtida na piabanha, considerando que $1 \mathrm{~g}(\sim 1 \mathrm{ml})$ de ova apresentou cerca de 700 ovócitos, é compatível com a tendência mostrada na Tab. 2, que demonstra que ovócitos maiores necessitam de mais espermatozóides para fecundação.

Tabela 2. Razão ótima de espermatozóides $\left(\mathrm{spt}_{3}\right)$ por ovócito de acordo com o tamanho dos ovócitos em algumas espécies. Espécies de peixe com ovócitos maiores do que a da piabanha são citadas acima desta e as com ovócitos menores, abaixo

\begin{tabular}{|c|c|c|c|}
\hline Espécie & $\begin{array}{l}\text { Indicativo do tamanho do } \\
\text { ovócitos (ovócitos/ml ou } \\
\text { diâmetro do ovócito) }\end{array}$ & $\begin{array}{c}\text { Razão ideal } \\
\text { sptz x } 10^{3} \text { /ovócito }\end{array}$ & Autor \\
\hline Thymallus thymallus & 40 ovócitos $/ \mathrm{ml}$ & $1200-1600$ & Lahnsteiner (2000) \\
\hline Esox lucius & Diâmetro $=2 \mathrm{~mm}$ & 700 & Marcel (1981) \\
\hline Oncorhynchus mykiss & Diâmetro $=4 \mathrm{~mm}$ & $\begin{array}{l}200 \\
300\end{array}$ & $\begin{array}{c}\text { Silveira et al. (1988) } \\
\text { Billard (1975) }\end{array}$ \\
\hline Coregonus lavaretus & 150 ovócitos $/ \mathrm{ml}$ & $300-500$ & Lahnsteiner (2000) \\
\hline Hippoglossus hippoglossus & Diâmetro $=3 \mathrm{~mm}$ & 1600 & Suquet et al. (1995) \\
\hline Brycon insignis & $\begin{array}{c}701 \text { ovócitos } / \mathrm{g} \\
\text { Diâmetro }=1,3 \mathrm{~mm}\end{array}$ & 314 & $\begin{array}{l}\text { Presente trabalho } \\
\text { Sousa (2004) }\end{array}$ \\
\hline Cyprinus carpio & 1500 ovócitos/g & 13 & Marcel (1981) \\
\hline Scophthalmus maximus & Diâmetro $=1 \mathrm{~mm}$ & 6 & Suquet et al. (1995) \\
\hline
\end{tabular}

As espécies T. thymallus (Lahnsteiner, 2000), E. lucius (Marcel, 1981), C. lavaretus (Lahnsteiner, 2000), H. hippoglossus (Suquet et al., 1995) apresentam ovócitos maiores que a piabanha e, provavelmente por isso, necessitam de mais células espermáticas para fecundar ovócitos. De forma análoga, as menores razões ótimas espermatozóides/ovócito verificadas no $S$. maximus (Suquet et al., 1995) e no C. carpio (Marcel, 1981) podem ser explicadas pelo fato de seus ovócitos serem menores que os encontrados na piabanha. A mesma relação não foi verificada na truta $O$. mykiss que, apesar de apresentar ovócitos de maior diâmetro, mostrou proporção ótima espermatozóides/ovócito menor que a piabanha. Segundo Suquet et al. (1995), a distância a ser percorrida pelo espermatozóide, que depende da velocidade espermática e tempo de motilidade, influencia na capacidade fecundante. Assim, é possível que os espermatozóides de truta tenham movimento mais rápido e duradouro, sendo necessária menor quantidade para fecundar um ovócito. 
Considerando-se que, em média, a concentração do sêmen da piabanha é de aproximadamente $25 \times 10^{9}$ espermatozóides/ml e que cada $1 \mathrm{~g}$ de desova apresenta cerca de 700 ovócitos, recomenda-se, na rotina de desova induzida da piabanha, a utilização de, pelo menos, $0,9 \mathrm{ml} \mathrm{de}$ sêmen para cada $100 \mathrm{~g}$ de ovócitos.

\section{AGRADECIMENTOS}

Ao CNPq, FAPERJ, pelo auxílio financeiro, e ao projeto Piabanha, por ceder o espaço físico e os peixes.

\section{REFERÊNCIAS BIBLIOGRÁFICAS}

ANDRADE-TALMELLI, E.F.; KAVAMOTO, E.T. ROMAGOSA, E. et al. Embryonic and larval development of the "piabanha", Brycon insignis, Steindachner, 1876 (Pisces, Characidae). Bol. Inst. Pesca, v.27, p.21-28, 2001a.

ANDRADE-TALMELLI, E.F.; KAVAMOTO, E.T.; FENERICH-VERANI， N. Características seminais da piabanha, Brycon insignis (Steindachner, 1876), após estimulação hormonal. Bol. Inst. Pesca, v.27, p.149-154, $2001 b$.

BILLARD, R. L'insemination artificielle de la truite, Salmo gairdneri Richardson. V. Effets de la diluition et définition du rapport optimum gamètes/dilueur. Bull. Fr. Piscicult., v.257, p.121-135, 1975.

BILLARD, R.; PETIT, J.; JALABERT, B. et al. Artificial insemination in trout using a sperm dilluent. In: BLAXTER, J.H.S. (Ed.). The early life history of fish. Berlin, Heidelberg, New York: Springer-Verlag, 1974. p.715-723.

CÓSER, A.M.L.; GODINHO, H.P.; SATO, Y. Capacidade de fertilização do sêmen de Prochilodus marggravii (curimatá-pacu) congelados sob forma de "pellets". In: ENCONTRO ANUAL DE AQÜICULTURA, 10., Belo Horizonte, Anais..., Belo Horizonte, 2000. p.56-59.

FAUVEL, C.; SAVOYE, O.; DREANNO, C. et al. Characteristics of sperm of captive seabass in relation to its fertilization potential. J. Fish Biol., v.54, p.356-369, 1999.

INSTRUÇÃO normativa $n^{\circ}$ 05/04 - Reconhecimento como espécies ameaçadas de extinção e espécies sobreexploradas (invertebrados aquáticos e peixes). Brasília: Ministério do Meio Ambiente. Diário Oficial da União, Brasília, 21 Mai. 2004.

KAVAMOTO, E.T.; SILVEIRA, W.F.; GODINHO, H.M. et al. Conservação em nitrogênio líquido do sêmen de Prochilodus scrofa Steindachner 1881. Bol. Inst. Pesca, v.16, p.29-36. 1989.

KAVAMOTO, E.T.; SILVEIRA, W.F.; RIGOLINO, M.G. et al. Produção espermática e teste de fertilização do sêmen de truta arco-íris, Salmo irideus Gibbons no primeiro ciclo reprodutivo. Bol. Inst. Pesca, v.14, p.51-62, 1987.

LAHNSTEINER, F. Semen cryopreservation in the salmonidae and in the northern pike. Aquac. Res., v.31, p.245-258, 2000.

MARCEL, J. Contrôle de la reproduction et gestions des gamètes de quelques espèces de poissons téléostéens. Lyons: École Pratique des hautes Études, 1981. 132f.

MOCCIA, R.D.; MUNKITTRICK, K.R. Relationship between the fertilization of rainbow trout (Salmo gairdneri) eggs and motility of spermatozoa. Theriogenology, v.27, p.679-688, 1987.

NOMURA, H. Dicionário dos peixes do Brasil. Brasília: Editerra, 1984. 482p.

RIBEIRO, R.I.M.A. Criopreservação do sêmen do piau-açu Leporinus macrocephalus (Garavello e Britski, 1998). 2001. 65f. Dissertação (Mestrado) - Universidade Federal de Minas Gerais, Belo Horizonte.

SILVA, E.B. Avaliação comparativa da utilização do sêmen criopreservado e fresco na fertilização dos óvulos de curimatá Prochilodus lineatus (Valenciennes, 1836). 2000. 49f. Dissertação (Mestrado) - Universidade Federal de Santa Catarina, Florianópolis.

SILVEIRA, W.F.; KAVAMOTO, E.T.; CESTAROLLI, M.A. et al. Avaliação espermática, preservação criogênica e fertilidade do sêmen do pacu, Piaractus mesopotamicus (Holmberg, 1887), proveniente de reprodução induzida. Bol. Inst. Pesca, v.17, p.1-13. 1990.

SILVEIRA, W.F.; KAVAMOTO, E.T.; RIGOLINO, M.G. et al. Fertilidade do sêmen da truta arco-íris, Salmo irideus Gibbons, em diferentes concentrações de espermatozóides por óvulo. Bol. Inst. Pesca, v.15, p.51-57. 1988.

SILVEIRA, W.F.; KAVAMOTO, E.T.; RIGOLINO, M.G. et al. Primeiros resultados de fertilização com sêmen congelado da truta arco-íris, Salmo irideus Gibbons no Brasil. Bol. Inst. Pesca, v.11, p.131-136. 1984.

SOUSA, G. Indução à desova, ontogenia inicial, etologia larval e alevinagem da piabanha (Brycon insignis Steindachner, 1877). 2004. 73f. Dissertação (Mestrado) Universidade Estadual do Norte Fluminense, Campos dos Goytacazes, RJ.

SUQUET, M.; BILLARD, R.; COSSON, J. et al. Artificial insemination in turbot (Scophthalmus maximus): determination of the optimal sperm to egg ratio and time of gamete contact. Aquaculture, v.133, p.83-90, 1995.

SUQUET, M.; DREANNO, C.; FAUVEL, C. et al. Cryopreservation of sperm in marine fish. Aquac. Res., v.31, p.231-243, 2000.

VAZZOLER, A.E.A.M. Biologia e reprodução de peixes teleósteos: teoria e prática. Maringá: Eduem, 1996. 169p.

WOYNAROVICH, E.; HORVATH, L. A propagação artificial de peixes de águas tropicais. Brasília: FAO/CODEVASF/CNPq, 1983. 200p. 